\title{
Prevalence and anti-microbial susceptibility pattern of methicillin resistant Staphylococcus aureus at a tertiary care hospital
}

\author{
Rajalakshmi Ramesh ${ }^{1 *}$, Padmavathi Karunakaran ${ }^{1}$, Dhivya Govindasamy ${ }^{1}$, \\ Kamalavarshini Paramasivamsasanger ${ }^{1}$, Prema Mariappan ${ }^{2}$
}

\author{
${ }^{1}$ Department of Pharmacy, Annamalai University, Annamalai Nagar, Tamil Nadu, India \\ ${ }^{2}$ Department of Surgery, Rajah Muthiah Medical College and Hospital, Annamalai University, Annamalai Nagar, \\ Tamil Nadu, India
}

Received: 24 June 2020

Accepted: 31 July 2020

\section{*Correspondence:}

Dr. Rajalakshmi Ramesh,

Email: rajiramesh30996@gmail.com

Copyright: (C) the author(s), publisher and licensee Medip Academy. This is an open-access article distributed under the terms of the Creative Commons Attribution Non-Commercial License, which permits unrestricted non-commercial use, distribution, and reproduction in any medium, provided the original work is properly cited.

\begin{abstract}
Background: To study about the prevalence and anti-microbial susceptibility pattern of methicillin resistant Staphylococcus aureus (MRSA).

Methods: Totally 110 non-repetitive Staphylococcus aureus isolates were enrolled in this study. Isolates from different clinical specimens like pus and blood obtained from patients in tertiary care hospital and Staphylococcus aureus was identified by conventional phenotypic methods. Complete antibiotic susceptibility testing of all MRSA isolates was determined by Kirby-Bauer disc diffusion method.

Results: Out of 110 isolates of $S$. aureus 60 were found to be methicillin-resistant Staphylococcus aureus (MRSA). The prevalence of MRSA was 54\%. Out of 60 isolates, male patients $37(63 \%)$ and female patients are $22(37 \%)$. Maximum numbers of isolates $25(41.6 \%)$ were from the age group of 51 to 60 years. Among these 60 isolates, all of them were found to be resistant to penicillin and oxacillin. In contrast, $98 \%$ of the isolates were found to be sensitive to linezolid. The sensitivity to chloramphenicol $70 \%$, co-trimoxazole $60 \%$, amikacin $58 \%$, clindamycin $43 \%$, ciprofloxacin $38 \%$, erythromycin $25 \%$.

Conclusions: The observed prevalence rate was 54\%. Linezolid showed the best therapeutic outcome against MRSA. Active screening plays an important role in control of MRSA.
\end{abstract}

Keywords: MRSA, Anti-microbial susceptibility, Kirby-Bauer method, Prevalence

\section{INTRODUCTION}

Staphylococcus aureus is a common pathogen that can cause various infections ranging from mild infections to life threatening sepsis in humans. ${ }^{1}$ Methicillin resistance Staphylococcus aureus (MRSA) was first reported in United Kingdom in $1961 .^{2}$ MRSA infection is now most common in India. Of one the study shows the incidence of MRSA differences from $25 \%$ western India $50 \%$ in south India. ${ }^{3}$ Presently more than $50 \%$ infections are caused by methicillin resistance strains of $S$. aureus. ${ }^{4}$
Before the introduction of penicillin Staphylococcus septicemia was extremely high in mortality rate.

Penicillin improved the prognosis of this infection. ${ }^{5}$ Treatment of infection caused by $S$. aureus has become difficult since the development of anti-microbial resistance of $S$. aureus. ${ }^{6}$ The development of resistant to beta lactam antibiotics like penicillin (methicillin, oxacillin) resulted in poor therapeutic outcome and therapeutic failure. ${ }^{14}$ MRSA is recognized as a major cause of nosocomial infections which cause the high burden on health care worldwide. Rapid and accurate 
identification of MRSA is necessary for to choose the appropriate therapy. ${ }^{7}$

After the emergence of MRSA as a nosocomial pathogen, there have been increase in number of life-threatening sepsis, endocarditis and osteomyelitis caused by MRSA have also been reported. ${ }^{8}$ The present study is aimed to study about the sensitivity pattern of MRSA.

\section{METHODS}

\section{Study duration}

This study was conducted at Rajah Muthiah Medical College Hospital, Annamalai University, Annamalai Nagar, Tamil Nadu for 3 months period between December 2019 to February 2020.

\section{Study population}

Totally 110 subjects were enrolled in this study. A 110 non-repetitive clinical isolates of $S$. aureus were isolated from various clinical samples.

\section{Method}

Isolates from different clinical specimens like pus, blood obtained from patients in tertiary teaching hospital and staphylococcus aureus was identified by conventional phenotypic methods. Complete antibiotic susceptibility profile was also determined by Kirby-Bauer disc diffusion method. ${ }^{12}$

\section{Identification of MRSA}

All the isolates of staphylococcus aureus were subjected to cefoxitin diffusion testing. The results were interpreted according to CLSI guidelines 2013. An inhibition zone diameter $<21 \mathrm{~mm}$ was reported as methicillin resistant and $>22 \mathrm{~mm}$ was reported as methicillin sensitive. ${ }^{10}$

\section{Kirby-Bauer disc diffusion method}

It is widely used test antibiotic susceptibility test which helps to choose the antibiotic should be used in treating infection. Mueller-Hinton $(15 \times 150 \mathrm{~mm})$ agar used in this method is very high in protein and thoroughly tested for its composition and $\mathrm{pH}$ level. It has three steps. ${ }^{10}$

Step-1: Preparation of bacterial suspension.

Step-1: Inoculation of Mueller Hinton agar.

Step-3: Reading and interpreting zone sizes.

\section{Procedure}

A sterile cotton swab was dipped into a suspension which was adjusted to $0.5 \mathrm{McFarland}$ turbidity. After the swab was streaked uniformly into $\mathrm{MH}$ agar and antibiotic sensitivity of the MRSA isolates against various antibiotics (Table 1) were determined by modified KirbyBauer method and incubated at $35^{\circ} \mathrm{C}$ for $18-24 \mathrm{~h}$. All inoculum on MHA were suspension of pure isolates in physiological saline with density equivalent to a 0.5 McFarland turbidity standard. Antibiotic sensitivity testing and result interpretation will be according to CLSI standards. ${ }^{11}$ Antibiotic vancomycin was not tested in this study (Table 1).

Table 1: Antibiotics tested against MRSA isolates by Kirby-Bauer disc diffusion method.

\begin{tabular}{|ll|}
\hline Antibiotic & Concentration \\
\hline Erythromycin & $15 \mu \mathrm{g}$ \\
\hline Clindamycin & $2 \mu \mathrm{g}$ \\
\hline Co-trimoxazole & $1.25 / 23.7 \mu \mathrm{g}$ \\
\hline Ciprofloxacin & $5 \mu \mathrm{g}$ \\
\hline Chloramphenicol & $30 \mu \mathrm{g}$ \\
\hline Amikacin & $30 \mu \mathrm{g}$ \\
\hline Gentamycin & $10 \mu \mathrm{g}$ \\
\hline Linezolid & $30 \mu \mathrm{g}$ \\
\hline Penicillin & $10 \mathrm{units}$ \\
\hline
\end{tabular}

\section{RESULTS}

Out of 110 isolates of S. aureus 60 were found to be methicillin-resistant Staphylococcus aureus (MRSA). The prevalence of MRSA was 54\%. Out of 60 patients from whom MRSA were isolated, male patients $37(63 \%)$ and female patients are $22(37 \%)$ (Table 2).

Table 2: Gender wise distribution.

\begin{tabular}{|lll|}
\hline Gender & No. of isolates & $\%$ \\
\hline Male & 37 & 63 \\
\hline Female & 22 & 37 \\
\hline
\end{tabular}

Table 3: Age wise distribution.

\begin{tabular}{|lll|}
\hline Age (in years) & No. of isolates & $\%$ \\
\hline $\mathbf{1 8 - 3 0}$ & 12 & 20 \\
\hline $\mathbf{3 1 - 4 1}$ & 10 & 16.6 \\
\hline $\mathbf{4 0 - 5 0}$ & 13 & 21.6 \\
\hline $\mathbf{5 1 - 6 0}$ & 25 & 41.6 \\
\hline
\end{tabular}

The age of the patients from whom MRSA were obtained ranged from 18 years to 70 years of age. It was noticed that amongst the 60 patients, maximum numbers of isolates were from the age group of 51 to 60 years comprising $25(41.6 \%)$ of the total followed by the age group 41-50 years $21.6 \%$. Table 2 shows the age wise distribution of the various isolates of MRSA (Table 3). The various clinical samples which from MRSA were isolated are pus $81 \%$ and blood $19 \%$. The most common clinical sample is pus. 
Among these 60 isolates, all of them were found to be resistant to penicillin and oxacillin. In contrast, most of them were found to be sensitive to linezolid $98 \%$. The sensitivity to chloramphenicol $70 \%$, co-trimoxazole $60 \%$, amikacin $58 \%$, clindamycin $43 \%$, ciprofloxacin $38 \%$, and erythromycin $25 \%$ (Table 4 ).

Table 4: Antibiotic sensitivity profile of MRSA isolates.

\begin{tabular}{|lll|}
\hline Antibiotic & No. of isolates & $\%$ \\
\hline Linezolid & 58 & 98 \\
\hline Chloramphenicol & 42 & 70 \\
\hline Co-trimoxazole & 36 & 60 \\
\hline Amikacin & 35 & 58 \\
\hline Clindamycin & 26 & 43 \\
\hline Ciprofloxacin & 23 & 38 \\
\hline Erythromycin & 15 & 25 \\
\hline Penicillin & 00 & 00 \\
\hline Oxacillin & 00 & 00 \\
\hline
\end{tabular}

\section{DISCUSSION}

MRSA is the most common cause for nosocomial infection worldwide. The prevalence of the MRSA infections as reported by National Nosocomial Infection Surveillance System (NNIS) in the US has been steadily increasing from $2.4 \%$ in $1974,5 \%$ in $1981,29 \% 1991$ to $43 \%$ in 1997.5 This study shows, out of 110 isolates of $S$. aureus 60 were found to be methicillin-resistant Staphylococcus aureus (MRSA). The prevalence of MRSA was 54\%.

Out of 60 patients from whom MRSA were isolated, male patients $37(63 \%)$ and female patients are $22(37 \%)$. The higher incidence of MRSA infections among male has been reported in this study. This result is similar to the study by Bhatt et al. ${ }^{9}$

In the present study, it was found that maximum number of isolates came from the age group of the patients from whom MRSA were obtained ranged from 18 years to 70 years of age. It was noticed that amongst the 60 patients, maximum numbers of isolates were from the age group of 51 to 60 years comprising 25 (41.6\%) of the total followed by the age group $41-50$ years $21.6 \%$. Then age group of 18 to 30 years $20 \%$ and then the age group of 31 to 40 years $16 \%$. This shows the controversial result to the study by Kalyani et al. ${ }^{11}$

The various clinical samples which from MRSA were isolated are pus $81 \%$ and blood $19 \%$. The most common clinical sample is pus. ${ }^{13}$

Linezolid showed excellent therapeutic activity against MRSA. All MRSA strains were resistant to penicillin and oxacillin which is similar to the by Ahmad et al similar results have been obtained in some major area of India. High degree sensitivity has been reported for chloramphenicol $70 \%$ similar to the study by Kalyani et al. ${ }^{11}$ Aminoglycosides such as gentamycin and amikacin show good sensitivity to MRSA strains showing $60 \%$ and $58 \%$ respectively. About $65 \%$ were found to be resistant to co-trimoxazole and clindamycin sensitivity in this study was $43 \%$. Sensitivity to ciprofloxacin and erythromycin ranged from $25-38 \%$ which shows most the of isolates were resistant to them. Similar results were also observed in the INSAR group study. ${ }^{3}$

\section{CONCLUSION}

The observed prevalence rate was 54\%. Linezolid showed the best therapeutic outcome against MRSA. Active screening plays an important role in control of MRSA.

\section{ACKNOWLEDGEMENTS}

We are very thankful to the patients, institution and those who helped us in this project successfully. I specially thanks to my father Ramesh Govidharasu and my friends.

\section{Funding: No funding sources}

Conflict of interest: None declared

Ethical approval: The study was approved by the Institutional Ethics Committee

\section{REFERENCES}

1. Lowy FD. Staphylococcus aureus infections. New England J Med. 1998;339(8):520-32.

2. Rolinson NG. Celbenin - resistant Staphylococci. British Med J. 1961;1(5219):125-6.

3. Indian Network for Surveillance of Antimicrobial Resistance (INSAR) group, India Methicillin resistant Staphylococcus aureus (MRSA) in India: prevalence and susceptibility pattern. Indian $\mathrm{J}$ Med Res. 2013;137:363-9.

4. Drago L. In vitro evaluation of antibiotics' combinations for empirical therapy of suspected methicillin resistant Staphylococcus aureus severe respiratory infections. BMC Infectious Diseases. 2007;7(111):2334-7.

5. Gardam MA. Is methicillin -resistant Staphylococcus aureus an emerging community pathogen? A review of literature. Can J Infect Dis. 2000;11(4):202-11.

6. Kumar P, Shukla I, Varshney S. Nasal screening of healthcare workers for nasal carriage of coagulase positive MRSA and prevalence of nasal colonization with staphylococcus aureus. Biology Med. 2011;27(1):62-4.

7. Uma S, Santhi M. Anti-microbial susceptibility pattern of methicillin resistant staphylococcus aureus. Sri Ramachandra J Med. 1998;339:520-32.

8. Pai V, Rao VI, Rao SP. Prevalence and Antimicrobial Susceptibility Pattern of Methicillinresistant Staphylococcus aureus (MRSA) Isolates at a Tertiary Care Hospital in Mangalore, South India. J Lab Physicians. 2010;2(2):82-4. 
9. Puneet MB, Gurpreet SB, Kundan T, Prashant J, Chaudhari $\mathrm{CN}$, Naveen $\mathrm{G}$, et al. Anti-microbial susceptibility profile of Methicillin-resistant Staphylococcus aureus at a Tertiary Care Centre. Archives Clin Microbiology. 2015;6(11).

10. Bauer AW, Kirby WMM, Sherris JC, Turck M. Antibiotic susceptibility testing by a standardized single disk method. Am J Clin Pathology. 1996;45:493-6.

11. Kalyani K, Karthika, Kumar J, Kumar SJ. Prevalence of Methicillin Resistant Staphylococcus Aureus Among Health Care Workers of Shri Satya Sai Medical College and Hospital: A Tertiary Care Centre. JDMS. 2012;(2):23-7.

12. Patel AK, Patel KK, Patel KR, Shah S, Dileep P. Time trends in the epidemiology of microbial infections at a tertiary care center in west India over last 5 years. J Assoc Physicians India. 2010;58:37-40.
13. Taj Y, Kazmi SU. Current pattern of antibiotic resistance in Staphylococcus aureus clinical isolates and the emergence of vancomycin resistance. J Coll Physicians Surg Pak. 2010;20(11):728-32.

14. Gopalakrishnan R, Kumar SD. Changing trends in antimicrobial susceptibility and hospital acquired infections over an 8-year period in a tertiary care hospital in relation to introduction of an infection control programme. $\mathrm{J}$ Assoc Physicians India. 2010;58:25-31.

Cite this article as: Ramesh R, Karunakaran P, Govindasamy D, Paramasivamsasanger K, Mariappan P. Prevalence and anti-microbial susceptibility pattern of methicillin resistant Staphylococcus aureus at a tertiary care hospital. Int J Basic Clin Pharmacol 2020;9:1371-4. 